\title{
Effect of Ouabain on Total Vascular Capacity in the Dog
}

\author{
Mark R. Goldman, Seth W. Wolk, David L. Rutlen, and Wm. John Powell, Jr., \\ Cardiac Unit, Department of Medicine, Massachusetts General Hospital, and \\ Department of Medicine, Harvard Medical School, Boston, \\ Massachusetts 02114
}

A B S T R A C T Whereas the cardiac effects of digitalis glycosides have been extensively studied, less is known of the extracardiac effects of the drug, in particular the effects on vascular capacity. We investigated the effects of parenteral ouabain on vascular capacity in the dog with particular emphasis on transhepatic resistance and its interaction with splanchnic and total intravascular capacity. We studied 49 dogs on total cardiopulmonary bypass in which the splanchnic and extrasplanchnic circulations could be separately perfused and drained, and the portal vein could be vented to systemic venous pressure. The results indicate: $(a)$ ouabain produces a net central displacement of blood at $30 \mathrm{~min}$ after administration of $150 \pm 70 \mathrm{ml}$ (SEM), (b) this displacement occurs despite a substantial increase in transhepatic resistance, although the early rise in transhepatic resistance may delay the net displacement of blood, and $(c)$ the decrease of overall vascular capacity is due to an effect of ouabain on the capacitance vessels of both the splanchnic and extrasplanchnic circulations. The peripheral vascular capacity effects of ouabain may therefore contribute to overall cardiac performance.

\section{INTRODUCTION}

Although much is known of the cardiac actions of digitalis glycosides, relatively less is known concerning the extracardiac effects of these drugs, in particular their effect on vascular capacity. Ross et al. (1) studied the effects of the aglycone acetylstrophanthidin on overall vascular capacity in dogs on total cardiopulmonary bypass. They concluded that acetylstrophanthidin caused a generalized venoconstriction and a marked rise in resistance to blood flow through the liver resulting in a net pooling of blood in the animal. Cotten and Stopp (2) studied the effects of the gly-

Received for publication 16 March 1981 and in revised form 28 July 1981.

Dr. Rutlen's current address is Yale University School of Medicine, New Haven, Conn. coside ouabain on peripheral capacity in dogs. They hypothesized increases in intravascular volume in the splanchnic vasculature within $10 \mathrm{~min}$ of the administration of ouabain based on findings of diminished venous return associated with a decrease in left and right atrial pressures; however, they did not make observations beyond $10 \mathrm{~min}$ after drug administration. Furthermore, they did not directly assess the effects of the drug on total vascular capacity, nor did they investigate whether changes in transhepatic resistance might influence splanchnic and total intravascular volume. Thus, the present study was undertaken to investigate the effect of the digitalis glycoside ouabain on total vascular capacity in the dog. Particular attention was directed to the time-course of the changes, the effect of ouabain on transhepatic vascular resistance, and to the interaction of splanchnic capacity and total intravascular volume changes.

\section{METHODS}

Animal preparation. 49 adult mongrel dogs of either sex, weighing between 18 and $25 \mathrm{~kg}$ were anesthetized with chloralose $(90 \mathrm{mg} / \mathrm{kg}$ i.v.) and urethane $(900 \mathrm{mg} / \mathrm{kg}$ i.v. $)$. After endotracheal intubation, ventilation was accomplished with a Bird Mark 7 constant pressure respirator (Bird Corp., Palm Springs, Calif.) with $97 \%$ oxygen and $3 \%$ carbon dioxide. A right lateral thoracotomy and a midline abdominal incision were performed. A total cardiopulmonary bypass preparation as has been described $(3,4)$ was used (Fig. 1A).

After the administration of heparin $(3 \mathrm{mg} / \mathrm{kg}$ i.v.), the femoral veins and superior vena cava were cannulated and the azygos vein was ligated. The venous blood from these veins was directed via an overflow column, the height of which was adjusted to produce any desired venous pressure, to a Harvey bubble oxygenator (model H-1000, C. R. Bard, Inc., Santa Ana, Calif.) and heat exchanger $\left(37^{\circ} \mathrm{C} \pm 0.5^{\circ} \mathrm{C}\right)$ and returned through a variable speed calibrated roller pump (Cardiovascular Instruments, Wakefield, Mass.) to the femoral arteries. 38 dogs had the central venous pressure set at $8 \mathrm{~cm} \mathrm{H}_{2} \mathrm{O} ; 11$ had the CVP set at $1 \mathrm{~cm} \mathrm{H}_{2} \mathrm{O}$. To exclude the pulmonary, bronchial, and coronary circulations, the aorta ( $2 \mathrm{~cm}$ above the aortic valve) and the pulmonary hila were cross-clamped. Drains were placed in the right and left ventricular cavities to assure adequacy of cross-clamping. The rate of pumping was maintained constant (except where 
noted) throughout each experiment. The oxygenator was calibrated with a scale of $20-\mathrm{ml}$ increments (from 0 to 3,000 $\mathrm{ml}$ ) before each experiment so that changes in oxygenator volume could be observed as the reciprocal of changes in total vascular capacity.

In 22 dogs the splanchnic venous blood flow was separately drained. The inferior vena cava was ligated just inferior to the liver. The inferior vena cava was then cannulated in the chest in retrograde fashion to drain the hepatic venous outflow, which was directed through an overflow column, the height of which was set to the same level as the central venous pressure. The hepatic venous flow was then returned to the oxygenator. Timed volumetric collections of splanchnic venous flows were taken for $30 \mathrm{~s}$ at $3-\mathrm{min}$ intervals throughout each experiment.

In six animals, to eliminate the effect of changing transhepatic resistance on overall capacity, the portal vein was cannulated just proximal to its bifurcation at the porta hepatis, and the distal portal vein was ligated at its bifurcation. The portal venous outflow was directed to the oxygenator via an adjustable overflow column to maintain portal pressure constant. The portal pressure was adjusted to be the same as the central venous pressure.

In six dogs, the splanchnic circulation and peripheral circulation were both separately perfused and drained. Drainage of the splanchnic circulation was accomplished as described above. The cranial and caudal mesenteric arteries and the celiac axis (which was ligated adjacent to the aorta) were isolated, cannulated, and perfused by a variable speed calibrated roller pump (Fig. 1B). Splanchnic arterial inflow was maintained constant throughout each experiment. In these six dogs, to investigate the effect of ouabain on the splanchnic vessels alone, the spleens were surgically removed.

In six dogs, to investigate the effects of ouabain on the extrasplanchnic circulation, the splanchnic organs were surgically removed. The cranial and caudal mesenteric vessels (arteries and veins) and the celiac axis were ligated and the splanchnic vicera (stomach, liver, spleen, mesentery, small intestine, and colon) were removed.

In four dogs in which ouabain was not administered, to investigate the effect of arterial redistribution from the splanchnic to extrasplanchnic circulation, the splanchnic and extrasplanchnic circulations were separately perfused and drained. The roller pumps that controlled the inflow to these circuits were adjusted so as to reduce splanchnic flow by $10 \%$ for $20 \mathrm{~min}$ and another $13 \%$ for an additional $10 \mathrm{~min}$. The total reduction in splanchnic flow was $23 \%$, which was equal to the mean fall in splanchnic flow in the nonseparately perfused experiments. The extrasplanchnic pump was concurrently increased by the same absolute amount so as to keep total arterial flow constant.

Drug administration. Ouabain (G-Strophanthidin, Eli Lilly \& Co., Indianapolis, Ind.) was injected as a bolus into the venous reservoir in 6 dogs and into the arterial cannulae in 39 animals. The amount of ouabain administered was 2 mg. In animals in which splanchnic and extrasplanchnic circulations were separately perfused, $1.5 \mathrm{mg}$ of ouabain was simultaneously injected into the extrasplanchnic arterial cannula and $0.5 \mathrm{mg}$ was injected into the splanchnic arterial cannula. In three additional dogs on total bypass, ouabain levels were determined from the reservoir blood at $0,5,15$, and $30 \mathrm{~min}$ after the intraarterial administration of ouabain. The method used for ouabain determination was a radioimmunoassay described by Selden and Smith (5).

In six dogs, 1 gm phenoxybenzamine (Dibenzyline, SmithKline \& French Laboratories, Philadelphia, $\mathrm{Pa}$.) was injected into the oxygenator to achieve alpha adrenergic blockade. After alpha adrenergic receptor blockade, no response to an intraarterial injection of $100 \mu \mathrm{g}$ phenylephrine

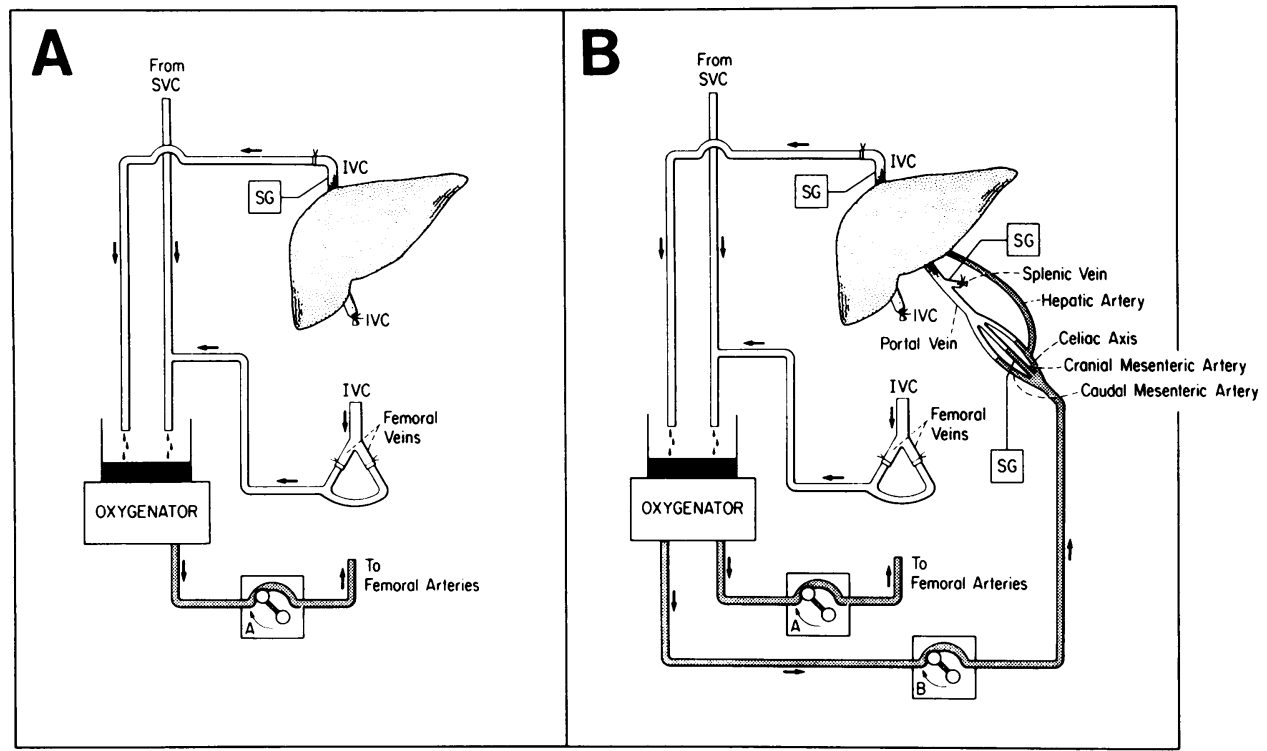

FIGURE 1 Schematic drawings of the experimental preparations used in these experiments. Panel A diagrams the total bypass preparation in which the splanchnic and extrasplanchnic circulations are separately drained. Panel B diagrams the preparation in which the splanchnic and extrasplanchnic circulations are separately perfused and drained. SVC, superior vena cava; IVC, inferior vena cava; SG, strain gauge. (See text for details). 
(Neosynephrine, Winthrop Laboratories, New York) was observed.

To test specificity of the alpha adrenergic blockade, three dogs were placed on total cardiopulmonary bypass with separately drained splanchnic and extrasplanchnic circulations. Before phenoxybenzamine administration $10 \mu \mathrm{g}$ norepinephrine (Levophed, Breon Laboratories, Inc., New York) was injected as a bolus, and prompt rises in mean arterial blood pressure of 7,7 , and $10 \mathrm{~mm} \mathrm{Hg}$, respectively were observed. Angiotensin II (Ciba-Geigy Corp., Summit, N. J.) $(100 \mu \mathrm{g})$ was also injected as a bolus intraarterially, and rises in mean blood pressure of 25,7 , and $12 \mathrm{~mm} \mathrm{Hg}$ were observed. Phenoxybenzamine was then administered into the oxygenator reservoir and each animal was retested with norepinephrine and agiotensin II. Intraarterial norepinephrine injections of either $10 \mu \mathrm{g}$ or of $1 \mathrm{mg}$ produced no detectable rise in mean arterial blood pressure. Intraarterial injections of angiotensin II $(100 \mu \mathrm{g})$ produced rises in mean blood pressure of 12,12 , and $20 \mathrm{~mm} \mathrm{Hg}$. The rise in blood pressure produced by angiotensin II before phenoxybenzamine administration (14.7 $\mathrm{mm} \mathrm{Hg} \pm 5.4 \mathrm{SEM}$ ) was not different from the rise in mean blood pressure caused by an equivalent dose of angiotensin II after phenoxybenzamine (14.7 $\mathrm{mm} \mathrm{Hg} \pm 2.7$ SEM). In further support of the specificity of phenoxybenzamine, this agent was shown not to affect the increase in transhepatic resistance in the dog produced by acetylcholine infusion (4).

In two dogs, to evaluate the contribution of ouabain-induced changes in vagal tone on transhepatic resistance, atropine (Dosette, Elkins-Sinn, Inc., Cherry Hill, N.Y.) was administered before the control period. These two animal preparations had separately drained splanchnic and extrasplanchnic circulations but without separate perfusion of these circuits. The spleens were removed in these two animals. In these experiments $20 \mathrm{mg}$ of atropine was administered into the oxygenator over $5 \mathrm{~min}$. This dose of atropine has been demonstrated to block the effects of infused acetylcholine and of vagal stimulation on transhepatic resistance (4). Both before and after atropine administration, $6 \mu \mathrm{g}$ of isoproterenol (Isuprel, Winthrop Laboratories), when injected into the mesenteric artery, was associated with the same decrease in splanchnic blood pressure of $15 \mathrm{~mm} \mathrm{Hg}$.

Data collection and analysis. All pressures were measured with Statham P23Db transducers (Statham Instruments, Inc., Oxnard, Calif.); the frequency response of the pressure measurement system was linear to $30 \mathrm{cps}$. Systemic and splanchnic arterial pressures were measured through short cannulae placed in the left brachial artery and in a branch of the cranial mesenteric artery in the intestinal arcade, respectively. Portal venous pressure was measured via a cannula inserted into a branch of the splenic vein and advanced to the portal vein. Hepatic vein wedge pressures were determined in five dogs using a 7 Swan-Ganz catheter (Edwards Laboratories, Santa Ana, Calif.), which was advanced in retrograde fashion through the hepatic vein into the liver. Hepatic and central venous pressure were measured from their respective overflow columns. All measured pressures were recorded on a Hewlett-Packard 7700 eightchannel recorder (Hewlett-Packard Co., Palo Alto, Calif.). Transhepatic resistance was calculated from the difference between portal vein pressure and hepatic vein pressure (centimeters $\mathrm{H}_{2} \mathrm{O}$ ) divided by the hepatic vein flow (milliliters per minute)

Dogs on total cardiopulmonary bypass slowly accumulate fluid, resulting in a progressive reduction in oxygenator volume. In the absence of interventions, the reduction in oxygenator volume is linear over time (3). To determine changes in animal volume brought about by an intervention, regression lines were drawn through the control period oxygenator volumes plotted against time and changes in dog blood volume were taken as differences between the extrapolated regression line and the observed oxygenator volumes. All animals were observed for a control period of at least $30 \mathrm{~min}$ and followed after ouabain administration for $30 \mathrm{~min}$. For purposes of illustration, only the last $20 \mathrm{~min}$ of the control periods are shown in the figures.

Changes in splanchnic vascular capacity were determined by integrating the difference between the mean hepatic vein flow of the control period and the observed flows over time following ouabain administration in those animals in which the splanchnic and extrasplanchnic circulations were separately perfused. Extrasplanchnic capacity was determined from the difference between total and splanchnic vascular capacities.

Statistical analysis. Significance of measured parameters (blood volume, flows, pressures, and transhepatic resistance) from control values was determined from grouped data by the method of Bonferroni (6). Individual data points were also tested for significance using a double-tailed, paired $t$ test. Significance was assumed if $P<0.05$.

\section{RESULTS}

When $2 \mathrm{mg}$ of ouabain was administered parenterally to 11 dogs on total cardiopulmonary bypass, the result was a net displacement of $150 \pm 70 \mathrm{ml}$ (SEM) of blood from the animal. The experimental results are shown in Fig. 2. Note that for the first 12 min after ouabain administration there was no significant alteration of blood volume but the displacement of blood became significant after $15 \mathrm{~min}$. During this initial $12 \mathrm{~min}$, six of the animals gained blood, three lost blood, and two did not change their blood volume. In 4 of the 11 dogs the venous blood from the splanchnic and the peripheral circulations were collected separately and the effect of ouabain on transhepatic resistance and splanchnic flow are shown. Note that transhepatic resistance increased promptly after the injection of ouabain and remained significantly elevated for $30 \mathrm{~min}$. The prompt increase in transhepatic resistance shortly after the injection of ouabain paralleled the prompt increase in systemic blood pressure, which under conditions of constant blood flow, represented an increase in systemic vascular resistance. Splanchnic blood flow decreased after ouabain administration but did not reach significance until $30 \mathrm{~min}$. In these four dogs there was a loss of volume of $148 \pm 51 \mathrm{ml} \mathrm{SEM}(P<0.05) 30 \mathrm{~min}$ after ouabain injection. In two dogs in which a hepatic vein wedge pressure was obtained the wedge pressure was identical to the portal pressure, indicating that the site of increase of transhepatic resistance was post sinusoidal.

In Fig. 3, alpha adrenergic receptor blockade with phenoxybenzamine did not alter the overall displacement of the blood from the animal, In these six animals in which $2 \mathrm{mg}$ of ouabain was administered after alpha 

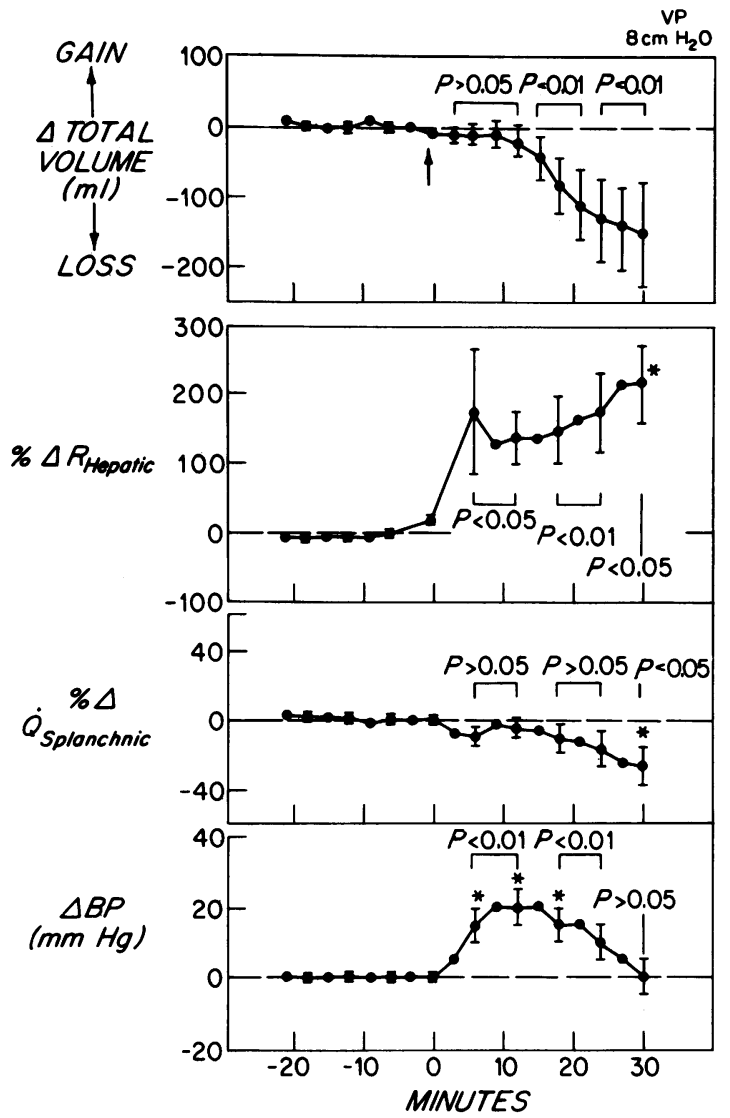

Figure 2 Data from dogs on total bypass after ouabain administration. The upper panel represents mean data from 11 dogs in which $2 \mathrm{mg}$ of ouabain was administered. The lower three panels represent mean data from 4 of the 11 dogs in which the splanchnic and extrasplanchnic circulations were separately drained. Note the prompt increase in both transhepatic resistance and blood pressure after ouabain injection. Note also the lack of a significant change in blood volume until $15 \mathrm{~min}$ after drug administration. Repatic $=$ transhepatic resistance, $Q_{\text {splanchnic }}=$ splanchnic blood flow, $\mathrm{BP}=$ blood pressure, $\mathrm{VP}=$ venous pressure. ${ }^{\circ} P<0.05$ using a double tailed, paired $t$ test. Mean control values were: ${ }^{R}$ hepatic, $13.5 \pm 5 \mathrm{~cm} \mathrm{H}_{2} \mathrm{O}-\mathrm{min}^{-1} \mathrm{SEM}$; Qsplanchnic, $479 \pm 127 \mathrm{ml} / \mathrm{min} \mathrm{SEM}$; BP, $65 \pm 5 \mathrm{~mm} \mathrm{Hg}$ SEM.

blockade, the total displacement of blood was $150 \pm 40$ $\mathrm{ml} \mathrm{SEM}$. Pharmacologic blockade of alpha adrenergic receptors, however, resulted in a significant reduction in the increase of transhepatic resistance at $12,18,24$, and $30 \mathrm{~min}$ after ouabain administration $(P<0.05)$ compared with the resistance response to ouabain in the unblocked state (Fig. 2). Similarly, the increase in systemic blood presure was significantly reduced at 6 , 12,18 , and $24 \mathrm{~min}$ in the alpha blocked animals compared with the unblocked animals after ouabain administration $(P<0.05)$. Interestingly, in comparing Fig. 2 and 3 after alpha adrenergic receptor blockade, the displacement of blood from the animal occurred earlier following ouabain administration than in the absence of alpha blockade. The fall in blood volume at 3,6 , and 9 min after ouabain administration is significantly greater in Fig. $3(P<0.05)$ than in Fig. 2 . In the range of 18 to 24 min transhepatic resistance did increase a small but significant amount in dogs that had previously received alpha receptor blockade.

In two additional dogs in which the splanchnic and extrasplanchnic circulations were separately drained and which had received atropine before the control period to eliminate ouabain-induced vagal contributions, ouabain produced increases in transhepatic resistance of 126 and $34 \%$ from control values of 10.0

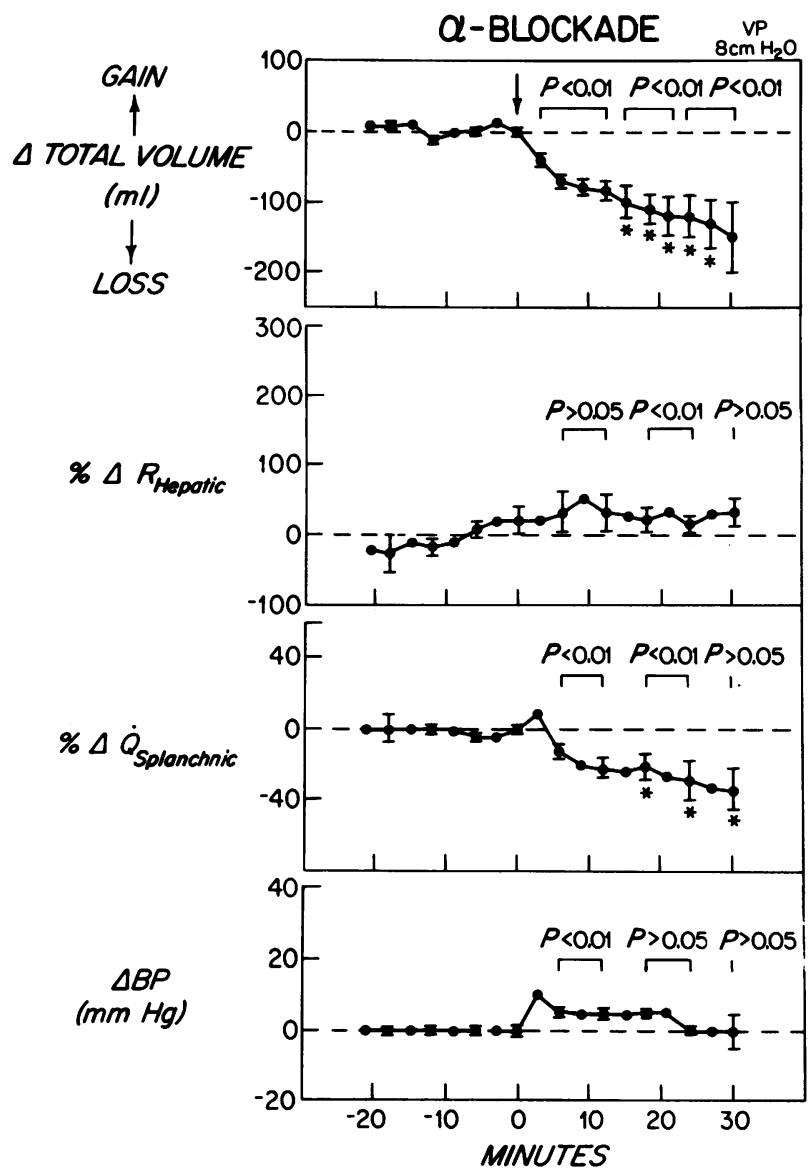

Figure 3 Data from six dogs on total bypass after ouabain administration in which alpha adrenergic receptor blockade was first achieved with phenoxybenzamine. Note the lack of an early significant increase in transhepatic resistance associated with an early significant displacement of blood from the animals. Note also the blunted blood pressure response to ouabain. ${ }^{\mathrm{R}}$ hepatic $=$ transhepatic resistance, $\mathrm{Q}_{\text {splanchnic }}=$ splanchnic blopd flow, $\mathrm{BP}=$ blood pressure, VP $=$ venous pressure. Mean control values were: ${ }^{\mathrm{R}}$ hepatic,

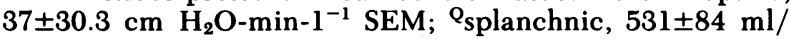
min SEM; BP, $50 \pm 5 \mathrm{~mm} \mathrm{Hg} \mathrm{SEM.}$ 
and $10.7 \mathrm{~cm} \mathrm{H}_{2} \mathrm{O}-\mathrm{min}^{-1} 1^{-1}$, respectively. In one of these animals in which a hepatic vein wedge pressure was obtained, the wedge pressure increased in parallel with the portal pressure after ouabain administration, indicating that the site of the increase in transhepatic resistance was post sinusoidal.

When the control central venous pressure was deliberately decreased from 8 to $1 \mathrm{~cm}_{2} \mathrm{O}$ to simulate more closely physiologic conditions that might occur in the absence of congestive heart failure, the mean resting transhepatic resistance was higher than at the central venous pressure of $8 \mathrm{~cm} \mathrm{H}_{2} \mathrm{O}(20.2 \pm 4.6 \mathrm{~cm}$ $\mathrm{H}_{2} \mathrm{O}-\mathrm{min}^{-1} \mathrm{1}^{-1} \mathrm{SEM}$ vs. $13.5 \pm 5.0 \mathrm{~cm} \mathrm{H}_{2} \mathrm{O}-\mathrm{min}-1^{-1} \mathrm{SEM}$ ), although the difference was not statistically significant. In these five animals the administration of $2 \mathrm{mg}$ of ouabain resulted in $90 \pm 65 \mathrm{ml}$ SEM displacement of blood from the animal (Fig. 4). This displacement was not significantly less at any time during its timecourse than that noted when the central venous pressure was $8 \mathrm{~cm} \mathrm{H}_{2} \mathrm{O}$ (Fig. 2). Note, as in Fig. 2, that there was no significant change in the animal's blood volume for the first $12 \mathrm{~min}$ after ouabain administration.

When the portal vein was vented to systemic venous pressure to eliminate the possible role of transhepatic resistance in influencing total displacement of blood (Fig. 5), the results (at a central venous pressure of 1 cm $\mathrm{H}_{2} \mathrm{O}$ ) revealed a greater displacement of blood from the animal of $190 \pm 120 \mathrm{ml} \mathrm{SEM}$, but at $30 \mathrm{~min}$ this displacement was not significantly different from the volume displacement noted in either Fig. 4 (at a central venous pressure of $1 \mathrm{~cm} \mathrm{H}_{2} \mathrm{O}$ ) or in Fig. 2 (at a central venous pressure of $8 \mathrm{~cm} \mathrm{H}_{2} \mathrm{O}$ ). However, note in Fig. 5 that the volume displacement from the animal was significant during the first $12 \mathrm{~min}$ when the portal vein was vented but was not significant in the absence of portal vein venting (Figs. 2 and 4 ). Note again the prompt increase in blood pressure, which was similar to that seen in Figs. 2 and 4 in the absence of alpha adrenergic receptor blockade.

When separate arterial perfusion was used to eliminate any arterial redistribution of blood from the splanchnic to the peripheral circulations, the total volume of blood displaced after ouabain injection at a central venous pressure of $8 \mathrm{~cm} \mathrm{H}_{2} \mathrm{O}$ was $270 \pm 150 \mathrm{ml}$ SEM (Fig. 6). This decrease in blood volume was not significantly different at any time from that which was achieved by ouabain administration in the absence of separate perfusion. In these separately perfused preparations splanchnic vascular resistance and peripheral vascular resistance (reflected in each of the blood pressure changes, respectively) increased promptly after ouabain administration. Fig. 7 shows the changes in peripheral blood volume and splanchnic blood volume derived from the experiments-the data from which

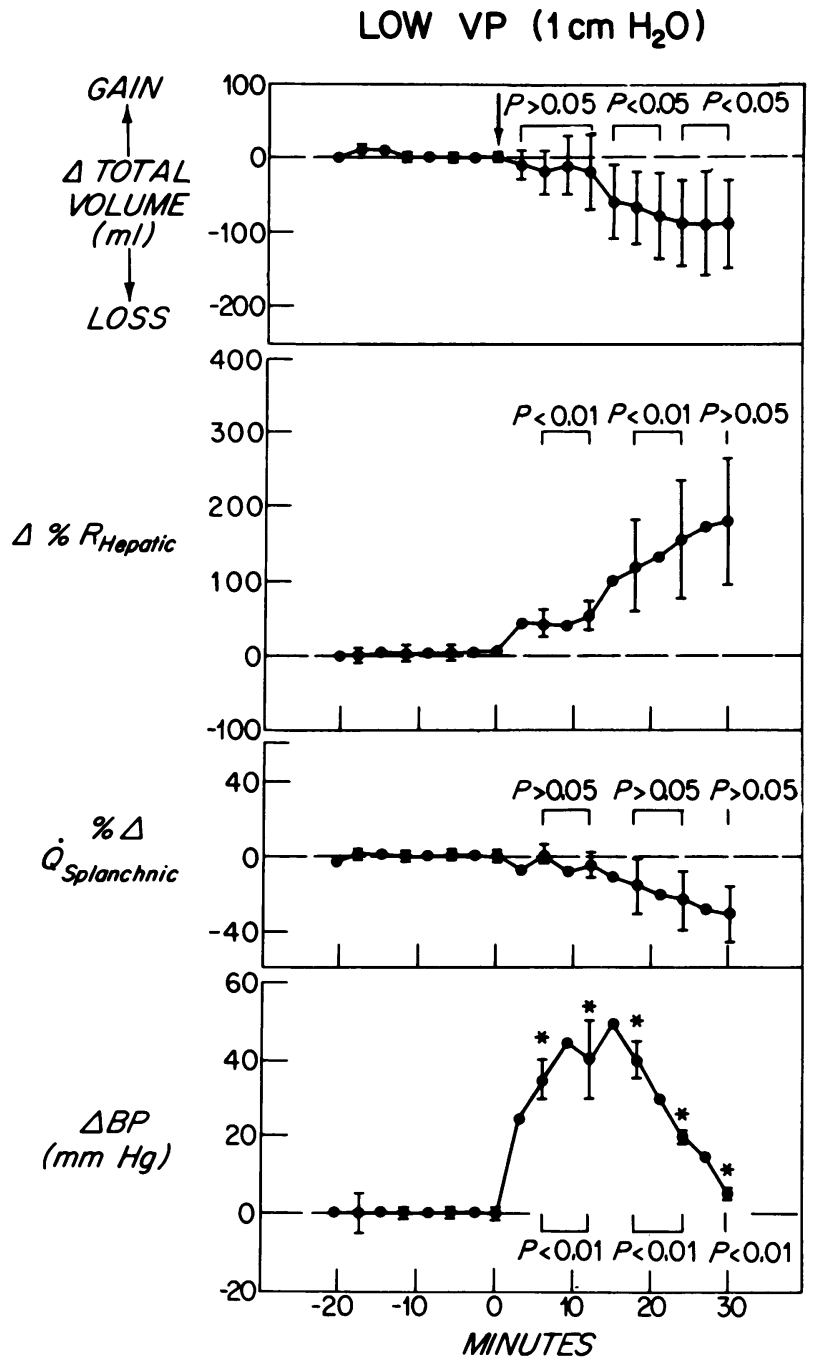

Figure 4 Data from five dogs on total bypass after ouabain administration in which the central venous pressure was set at $1 \mathrm{~cm} \mathrm{H}_{2} \mathrm{O}$ as opposed to $8 \mathrm{~cm} \mathrm{H}_{2} \mathrm{O}$ as in Figs. 2 and 3 . Note the absence of a significant change in blood volume in the first $12 \mathrm{~min}$ after ouabain injection. ${ }^{\mathrm{R}}$ hepatic $=$ transhepatic resistance, $Q_{\text {splanchnic }}=$ splanchnic blood flow, $\mathrm{BP}=$ blood pressure, $\mathrm{VP}=$ venous pressure . Mean control values were: ${ }^{\mathrm{R}}$ hepatic, $20.2 \pm 4.6 \mathrm{~cm} \mathrm{H} \mathrm{H}_{2} \mathrm{O}$-min$1^{-1} \mathrm{SEM}$ : Q splanchnic, 606 $\pm 60.4 \mathrm{ml} / \mathrm{min} \mathrm{SEM}$; BP, $80 \pm 5$ mm Hg SEM.

are displayed in Fig. 6. The changes in splanchnic blood volume were determined from the cumulative changes in splanchnic outflow, taking into account constant splanchnic inflow. The data on peripheral blood volume were obtained by subtraction. Note that both peripheral blood volume and splanchnic blood volume decreased significantly in the $30 \mathrm{~min}$ after parenteral ouabain.

Fig. 8 shows the total blood volume and blood pressure data from six eviscerated dogs in which the blood 


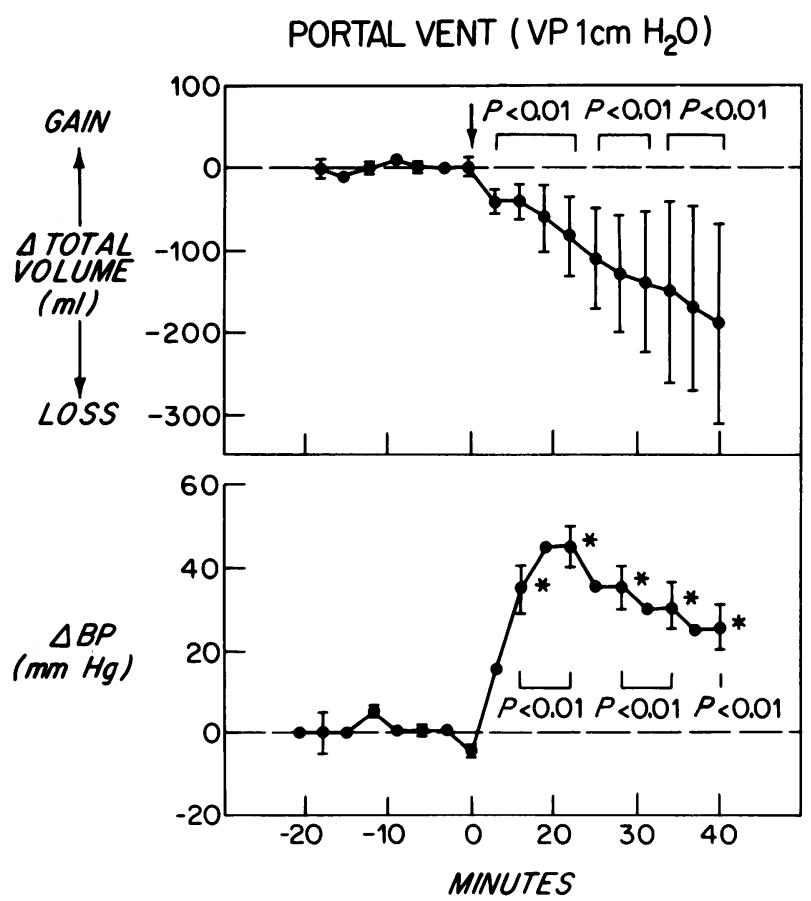

Figure 5 Data from six dogs on total bypass after ouabain administration in which the portal vein was vented to systemic venous pressure at $1 \mathrm{~cm} \mathrm{H}_{2} \mathrm{O}$. Note the early significant displacement of blood from the animals in the first 12 min after ouabain injection. $\mathrm{BP}=$ blood pressure, $\mathrm{VP}=\mathrm{ve}$ nous pressure. Mean control value for BP was $70 \pm 5 \mathrm{~mm} \mathrm{Hg}$ SEM

volume change represents the peripheral blood volume. Note the similarity in the volume change and the time-course of the volume change between the data in Fig. 8 and the data in the top panel of Fig. 7 in which the peripheral volume data were obtained by subtraction. The peripheral volume displaced in eviscerated dogs (Fig. 8) at the end of $30 \mathrm{~min}$ was $140 \pm 40$ $\mathrm{ml} \mathrm{SEM}$ and in animals with separate splanchnic and peripheral perfusion, it was $175 \pm 140 \mathrm{ml}$ SEM (Fig. 7). Therefore, even though the peripheral volume data in Fig. 7 were obtained by subtracting the actually measured splanchnic volume determinations from the measured overall volumes (Fig. 6), there is reasonably good correspondence with the net displacement of blood from the eviscerated animals.

Fig. 9 shows the results from experiments in which, in the absence of ouabain administration, redistribution of blood flow from the splanchnic to the peripheral circulation was simulated by mechanically reducing splanchnic inflow and mechanically increasing peripheral blood flow in animals in which the two arterial perfusion systems were separately cannulated. As can be seen in Fig. 9, simulating the arterial redistribution of blood flow which occurred with ouabain adminis- tration resulted in a net gain of $100 \pm 70 \mathrm{ml}$ SEM of blood. These data indicate that the loss of blood with ouabain administration is not due to arterial redistribution of blood flow from one circuit to another. The data imply that the blood loss with ouabain would have been greater were it not for this redistribution effect. This may account for the total blood loss in Fig. 6 (separate and constant perfusion experiments) being

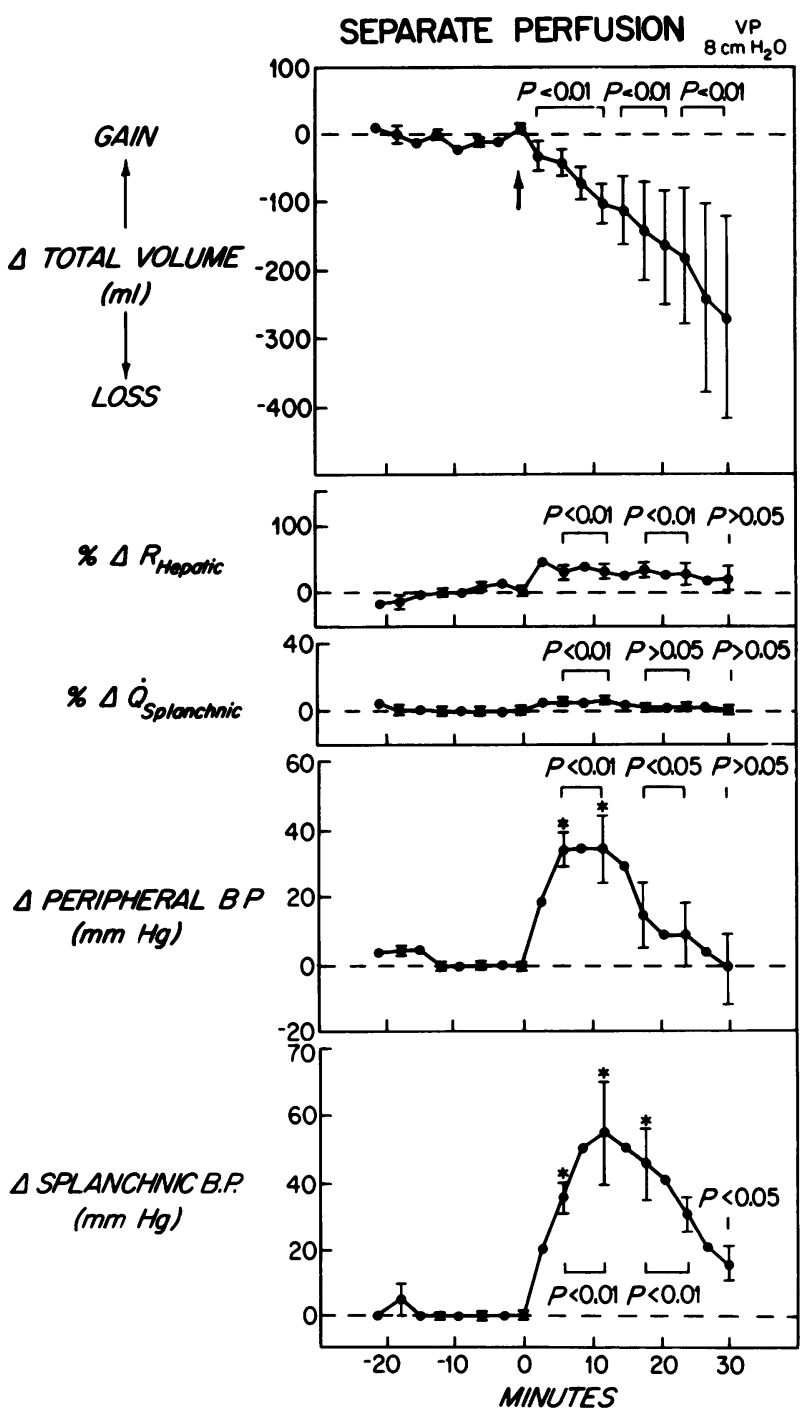

Figure 6 Data from six dogs on total bypass after ouabain administration in which the splanchnic and extrasplanchnic circulations were separately perfused and drained. Note the prompt increase in splanchnic blood pressure and peripheral (extrasplanchnic) blood pressure, both reflecting increased vascular resistance. ${ }^{\mathrm{R}}$ hepatic $=$ transhepatic resistance, ${ }^{Q_{\text {splanchnic }}}=$ splanchnic blood flow, $\mathrm{BP}=$ blood pressure, $V P=$ venous pressure. Mean control values were:

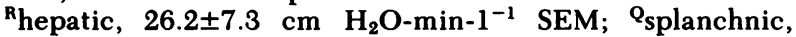
$319 \pm 54.2 \mathrm{ml} / \mathrm{min}$ SEM; BP, $65 \pm 10 \mathrm{~mm} \mathrm{Hg} \mathrm{SEM}$. 


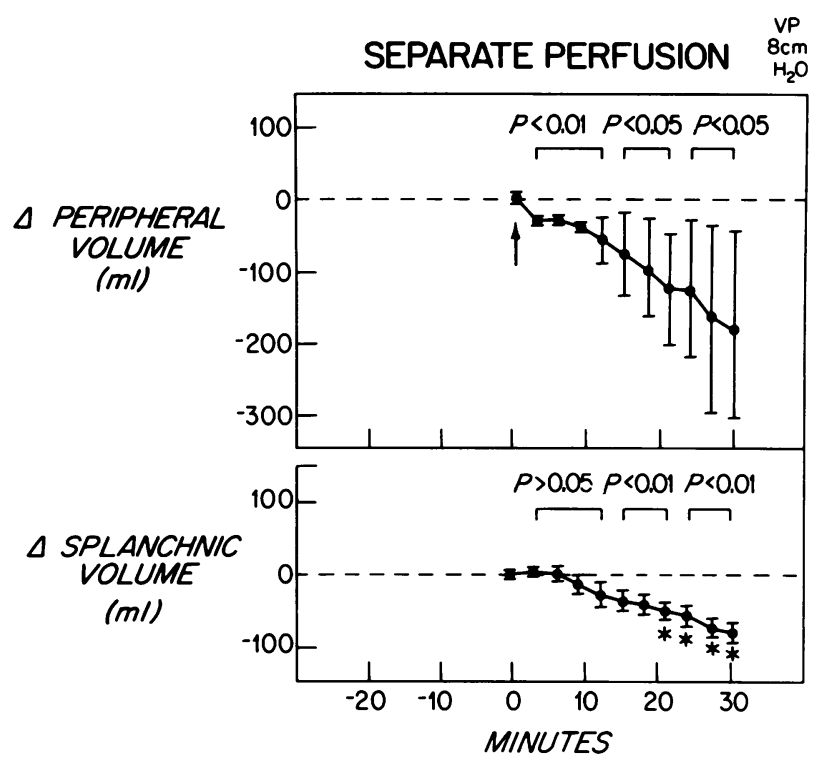

Figure 7 Data derived from the experiments shown in Fig. 6 . The lower panel represents the change in splanchnic blood volume as determined by the integration of splanchnic drainage flows over time. The upper panel represents the change in extrasplanchnic blood volume obtained by subtracting the splanchnic blood volume changes from the observed volume changes in the whole animal. VP $=$ venous pressure.

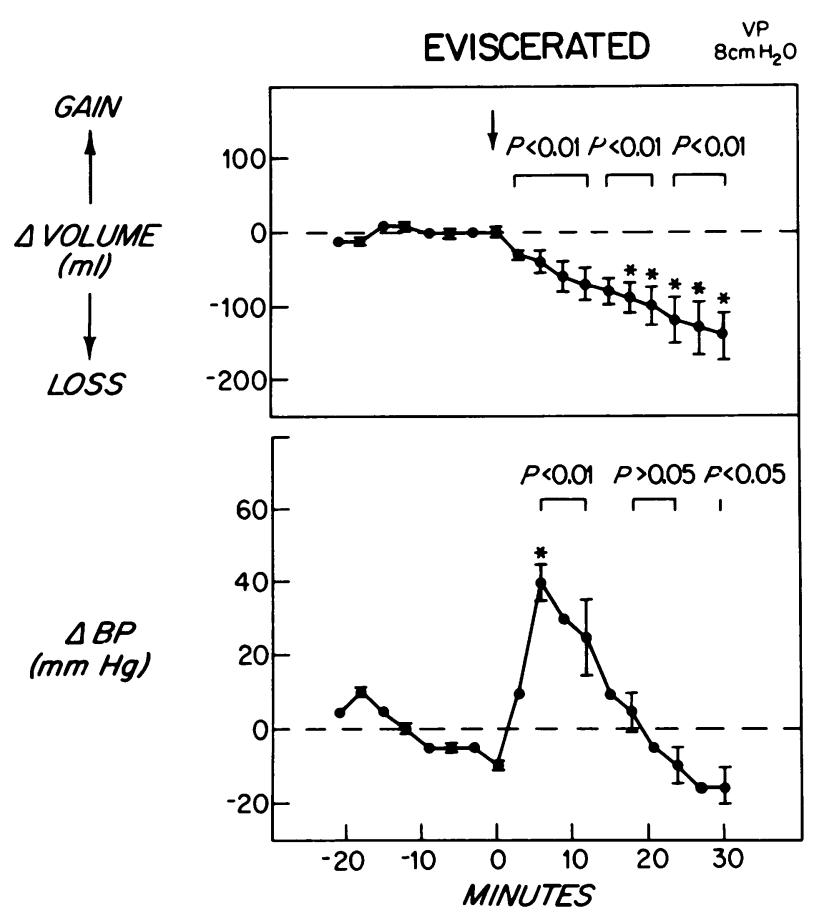

Figure 8 Data from six dogs on total bypass after ouabain administration in which the splanchnic circulation was surgically extirpated. BP $=$ blood pressure, $\mathrm{VP}=$ venous pressure. Mean control value for BP was $70 \pm 5 \mathrm{~mm} \mathrm{Hg} \mathrm{SEM}$.

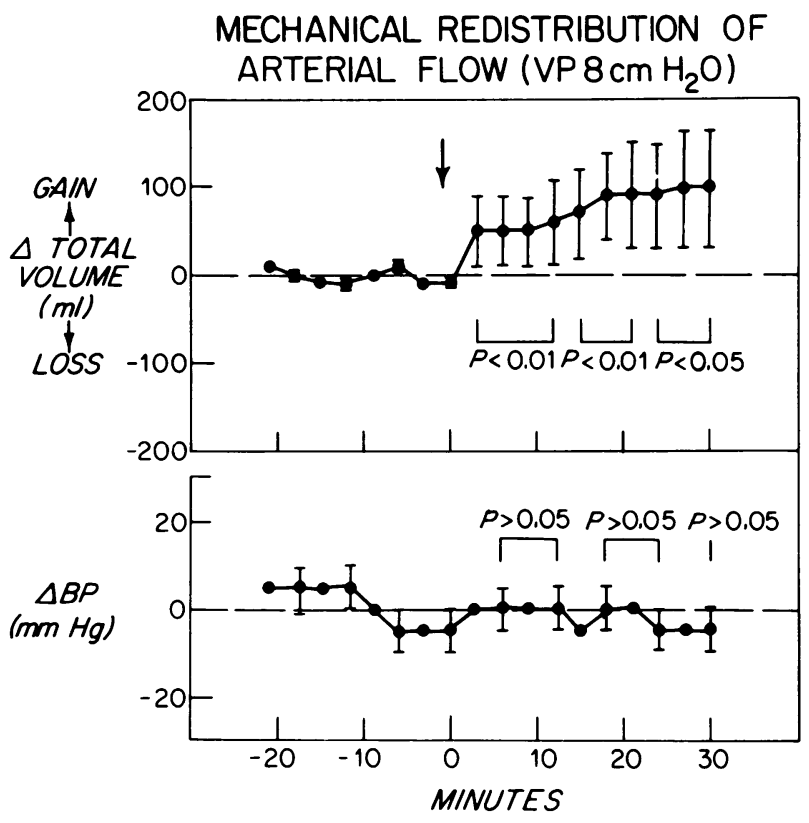

FIGURE 9 Data from four dogs on total bypass in which the splanchnic and extrasplanchnic circulations were separately perfused and drained. The roller pumps were adjusted (starting at $0 \mathrm{~min}$ ) to stimulate the ouabain-induced redistribution of blood flow from the splanchnic to the extrasplanchnic circulations as seen in Fig. 2. Note the increase in total intravascular volume when the mechanical redistribution occurred. The blood pressure plot illustrates the lack of change in peripheral blood pressure. VP $=$ venous pressure. Mean control value for BP was $85 \pm 5 \mathrm{mmHg}$ SEM.

greater than that in Fig. 2 in which arterial inflow was not controlled and redistribution allowed to occur.

The data from the seven different types of preparations used in these experiments are summarized qualitatively in Table I.

Ouabain levels were obtained on three dogs on total

TABLE I

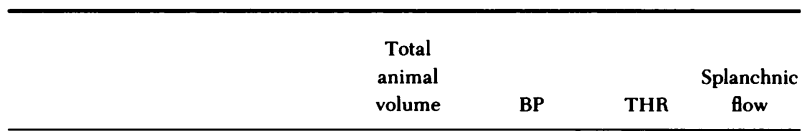

Total bypass No. $\alpha$ -

blockade

Total bypass $\alpha$-blockade

$\mathrm{CVP}=1 \mathrm{~cm} \mathrm{H} \mathrm{H}_{2} \mathrm{O}$

Portal vent

Separate perfusion

Eviscerated

Mechanical redistribution of

arterial inflow (no

ouabain)

$\begin{array}{clcc}\downarrow & \uparrow & \uparrow & \downarrow \\ \downarrow & \uparrow \text { (blunted) } & - & \downarrow \\ \downarrow & \uparrow & \uparrow \uparrow & \downarrow \text { (NS) } \\ \downarrow & \uparrow & \text { NA } & \downarrow \\ \downarrow & \uparrow & \uparrow & \text { NA } \\ \downarrow & \uparrow & \text { NA } & \text { NA } \\ & & & \\ \uparrow & & & \end{array}$

$\mathrm{BP}=$ blood pressure, $\mathrm{THR}=$ transhepatic resistance, $\mathrm{CVP}=$ central venous pressure, $\mathrm{NS}=$ not significant, $\mathrm{NA}=$ not applicable. 
bypass with separately drained splanchnic and extrasplanchnic circulations. Before the intraarterial administration of ouabain, there was no detectable ouabain in any sample. Mean values for ouabain at 5,15 , and $30 \mathrm{~min}$ after drug injection were $1.6 \mathrm{ng} / \mathrm{ml} \pm 0.4$ $\mathrm{SEM}, 1.0 \mathrm{ng} / \mathrm{ml} \pm 0.3 \mathrm{SEM}$, and $0.8 \mathrm{ng} / \mathrm{ml} \pm 0.3 \mathrm{SEM}$, respectively. The volume of distribution of the drug is not only the blood volume and extracellular space of the dogs, but also the volume of blood in the pump oxygenator.

\section{DISCUSSION}

The data demonstrate that the acute administration of ouabain is asociated with a decrease in total peripheral vascular capacity. This decrease in capacity occurs despite a substantial increase in transhepatic vascular resistance, which is mediated by an increase in alpha adrenergic receptor stimulation. The influence of the increase in transhepatic resistance, which would tend to pool blood in the splanchnic vasculature, is small, however, because splanchnic volume decreases with ouabain administration. The effect of ouabain on extrasplanchnic capacitance vessels also contributes to the decrease in total vascular capacity.

The decrease in total peripheral capacity is influenced initially by the increase in transhepatic resistance for the following reason. When the portal vein is not vented, ouabain administration is associated with no net change in vascular capacity during the first 10 min after administration. When the portal vein is vented, however, vascular capacity decreases during this early time period. Thus, in animals in which the portal vein has not been vented, it is likely that the rapid increase in transhepatic resistance, during the first 10 min after the acute administration of ouabain, tends to pool blood in the mesenteric vasculature. This effect opposes the net expression of blood resulting in no net change in blood volume over this period of time.

The experiments in which hepatic vein wedge pressure was monitored suggest that the location of the reactive vascular elements responsible for the resistance change is in the hepatic post sinusoidal vasculature. In the dog, contractile hepatic veins, contractile sublobular veins, and sinusoidal outlet sphincters have been anatomically identified $(7,8)$. Increases in transhepatic resistance could occur at each of these sites. Other studies on vascular capacity in the dog in response to beta agonists and to acetylcholine using hepatic vein wedge pressures to localize the site of altered transhepatic resistance have also demonstrated that the change in resistance in these preparations occurred in a postsinusoidal location as in this study $(3,4)$.

The elevation of transhepatic resistance is primarily mediated through stimulation of alpha adrenergic re- ceptors, Similarly, stimulation of alpha receptors is the major mechanism whereby intravenous digitalis administration elevates arterial vascular resistance as noted in Figs. 2 and 3 and our previous work (9-11). The work by Garan et al. (12) suggests that the central nervous system is the site of action of the increase in arterial resistance after digitalis administration. The alpha adrenergically mediated increase in transhepatic resistance with ouabain may also be mediated through the central nervous system, although, recently published data by Lorenz et al. (13) suggest that ouabain may release norepinephrine from neuronal stores in isolated venous segments. In the present study, even after alpha adrenergic receptor blockade with phenoxybenzamine, transhepatic resistance increases to a small extent after ouabain injection. This small increase could be due to one or more factors. First, digitalis is known to increase vagal activity and recent work suggests that enhanced cholinergic activity may increase transhepatic resistance (4). The presence of a substantial ouabain-associated increase in transhepatic resistance after atropine administration, however, makes it unlikely that increased vagal activity plays a prominent role in elevating transheptic resistance. Second, ouabain may directly increase transheptic resistance independent of alpha adrenergic receptor stimulation. Regardless of the mechanism of the increase in transhepatic resistance, the net decrease in vascular capacity $30 \mathrm{~min}$ after ouabain injection does not appear to be mediated through alpha adrenergic receptor stimulation. The mechanism of the effect on total vascular capacity in the alpha adrenergically blocked animals is not clear but is probably a direct effect of the drug on the capacitance vasculature as suggested by Mason and Braunwald (14) who observed ouabain-induced venoconstriction in the forearms of normal humans, unaltered by alpha adrenergic blockade with guanethidine.

The present data show that the overall capacity changes after ouabain administration occur at both high and low systemic venous pressure. The higher resting transhepatic resistance at a central venous pressure of $1 \mathrm{~cm} \mathrm{H}_{2} \mathrm{O}$ may reflect relatively less distention of the reactive vascular elements responsible for the resistance to transhepatic blood flow. Most of the experiments in the current study were performed with a central venous pressure of $8 \mathrm{~cm} \mathrm{H}_{2} \mathrm{O}$ to simulate more closely the condition of heart failure, a condition in which digitalis glycosides would be likely to be administered.

Previous work in dogs on total cardiopulmonary bypass has demonstrated that the administration of high doses of acetylstrophanthidin, an aglycone, was associated with an increase in transhepatic resistance which resulted in a net pooling of blood in the animal 
(1). In that study, when the portal vein was vented to the systemic venous circulation, blood was displaced from the animal. The present data show that the administration of more nearly therapeutic doses of ouabain, a cardiac glycoside, produces a net displacement of blood or a decrease in venous capacity despite the increase in transhepatic resistance. The difference between the present study and the previous study referred to above may relate both in the fact that acetylstrophanthidin is an aglycone and to the dosage used.

The net effect of ouabain in displacing blood centrally appears to be through effects on the splanchnic and extrasplanchnic capacitance circulations. The effects on these two vasculatures are manifest by the decrease in splanchnic volume in the animals with separate splanchnic perfusion and by the decrease in peripheral volume in the eviscerated animals. In support of the effect on these capacitance circulations are the observations that ouabain causes venoconstriction in isolated venous strips (13) from both the portal and lateral saphenous systems and increases venous tone in normal humans as measured by forearm plethysmography (14).

It is possible that the redistribution of arterial inflow between the splanchnic and extrasplanchnic peripheral circulations modifies the total volume displacement. As noted in Figs. 2 and 6 there is a tendency for a greater volume decrement when arterial redistribution is not allowed to occur. Furthermore, a contribution of arterial redistribution is manifest by the increase in total volume when arterial inflow is redistributed from the splanchnic to the peripheral circulation in the absence of ouabain (Fig. 9). The work of Caldini et al. (15) has also pointed to the importance of arterial redistribution of blood flow from one vascular bed to another in affecting overall intravascular volume. In our experimental preparation the peripheral vasculature appeared able to accomodate an increase in volume that was greater than the decrease in volume in the splanchnic vasculature. Whatever the mechanism whereby arterial redistribution affected total volume in the present study, it is clear that arterial redistribution did not contribute to the outward displacement of blood associated with ouabain administration.

Cotten and Stopp (2), found that $10 \mathrm{~min}$ after the intravenous injection of ouabain, left atrial pressure and cardiac output decreased. These decrements suggest a decrease in venous return to the left atrium and hence, a pooling of volume in the capacitance vasculature. In comparing their data with the present data that demonstrate a central displacement of blood, it should be noted that Cotten and Stopp (2) only reported data for the first $10 \mathrm{~min}$ after ouabain injection.
During this time period, some of the animals in our study demonstrated a peripheral pooling (six animals) and some a central displacement (three animals) resulting in no significant change in blood displacement in the overall series (Fig. 2). It was not until 15-21 min after ouabain injection that there was a significant central displacement of blood. Furthermore, the preservation of pulsatile flow in the Cotten and Stopp (2) study and the possibility of changes in arterial pulse pressure cannot explain the difference in results between their study and ours. In their study there were decreases in left atrial pressure and cardiac output irrespective of whether stroke volume increased or decreased after ouabain administration.

Thus, our data establish that the administration of ouabain results in a decrease in total vascular capacity despite an increase in transhepatic resistance that would tend to pool blood in the splanchnic vasculature. It is possible that the displacement of blood toward the central circulation would contribute to an increase in cardiac performance with ouabain in an animal not on cardiopulmonary bypass.

Any effect of ouabain on an intact animal or human would of course be a function of the drug's effect on the capacitance vasculature, the inotropic effect on the heart and reflex effects arising from direct neurogenic stimulation and indirect reflexes arising from altered hemodynamics. The mean displacement of blood from our animals on total cardiopulmonary bypass was 150 $\mathrm{ml}(7.5 \mathrm{ml} / \mathrm{kg}$ mean displacement $)$. Using a total vascular compliance of $2.0 \mathrm{ml} / \mathrm{mm} \mathrm{Hg} \mathrm{kg} \mathrm{mb}^{-1}$ body weight (16), the same blood displacement in an intact animal would correspond to an increase in mean systemic filling pressure of $3.75 \mathrm{~mm} \mathrm{Hg}$. Using Guyton's curves on the equilibrium between venous return and cardiac output (17), and assuming no alteration in cardiac contractility or reflex effects, this central shift of blood could increase cardiac output by more than $50 \%$. In the intact animal, reflex effects would be expected to attenuate the calculated increase in cardiac output.

In humans with heart failure, digitalis does diminish heart size and reduce pulmonary congestion, although not acutely. The predominant factor in the reduction of cardiomegaly is the inotropic effect of digitalis. One could speculate that were it not for the drug's effect on vascular capacity, the reduction in heart size would be more pronounced.

\section{ACKNOWLEDGMENTS}

Dr. Rutlen was the Paul Dudley White Fellow of the American Heart Association, Massachusetts affiliate, and was supported during this study by Research Fellowship award 13418-767 of the American Heart Associate Association, Cape and Islands Division of the Massachusetts affiliate. This study was supported in part by U.S. Public Health Service National 
Institutes of Health grant 1-RO1-HL18657, and by a grant from the Educational Foundation of America, Incorporated.

\section{REFERENCES}

1. Ross, J., E. Braunwald, and J. A. Waldhausen. 1960. Studies on digitalis. II. Extracardiac effects on venous return and on the capacity of the peripheral vascular bed. J. Clin. Invest. 39: 937-942.

2. Cotten, M. D., and P. D. Stopp. 1958. Action of digitalis on the nonfailing heart of the dog. Am. J. Physiol. 192: 114-120.

3. Rutlen, D. L., E. N. Supple, and W. J. Powell, Jr. 1981. $\beta$-Adrenergic regulation of total systemic intravascular volume in the dog. Circ. Res. 48: 112-120.

4. Supple, E. W., and W. J. Powell, Jr. 1981. The effect of acetylcholine on vascular capacity in the dog. J. Clin. Invest. 68: 64-74.

5. Selden, R., and T. W. Smith. 1972. Ouabain pharmacokinetics in dog and man: determination by radioimmunoassay. Circulation. 45: 1176-1182.

6. Morrison, D. F. 1976. Multivariate Statistical Methods. Second edition, McGraw-Hill Book Company, Inc., New York. 33-34.

7. Greenway, C. V., and R. D. Stark. 1971. Hepatic vascular bed. Physiol. Rev. 51: 23-65.

8. Knisely, M. D., F. Harding, and H. Debacker. 1957. Hepatic sphincters. Brief summary of present day knowledge. Science (Wash., D. C.). 125: 1023-1026.

9. Stark, J. J., C. A. Sanders, and W. J. Powell, Jr. 1972. Neurally mediated and direct effects of acetylstrophan- thidin on canine skeletal muscle vascular resistance Circ. Res. 30: 274-282.

10. Hamlin, N. P., J. T. Willerson, H. Garan, and W. J. Powell, Jr. 1974. The neurogenic vasoconstrictor effect of digitalis on coronary vascular resistance. J. Clin. Invest. 53: 288-296.

11. Sagar, K. B., E. C. Hanson, and W. J. Powell, Jr. 1977. Neurogenic coronary vasoconstrictor effects of digitalis during acute global ischemia in dogs. J. Clin. Invest. 60: 1248-1257.

12. Garan, H., T. W. Smith, and W. J. Powell, Jr. 1974. The central nervous system as a site of action for the coronary vasoconstrictor effect of digoxin. J. Clin. Invest. 54: 1365-1372.

13. Lorenz, R. R., D. A. Powis, P. M. Vanhoutte, and J. T. Shepherd. 1980. The effects of acetylstrophanthidin and ouabain on the sympathetic adrenergic neuroeffector junction in canine vascular smooth muscle. Circ. Res. 47: 845-854.

14. Mason, D. T., and E. Braunwald. 1964. Studies on digitalis. X. Effects of ouabain on forearm vascular resistance and venous tone in normal subjects and in patients in heart failure. J. Clin. Invest. 43: 532-543.

15. Caldini, P., S. Permutt, J. A. Waddell, and R. L. Riley, 1974. Effect of epinephrine on pressure, flow, and volume relationships in the systemic circulation of dogs. Circ. Res. 34: 606-623.

16. Shoukas, A. A., and K. Sagawa. 1971. Total systemic vascular compliance measured as incremental volumepressure ratio. Circ. Res. 28: 277-289.

17. Guyton, A. C. 1980. Circulatory Physiology III: arterial pressure and hypertension. W. B. Saunders Company, Philadelphia, $\mathrm{Pa}$. 